\title{
Entrepreneurship Education: Tacit Knowledge and Innovation Transfer. An Analysis Through Nonaka's Model
}

\author{
Nada Rih \\ PhD student, Mohammed V Souissi University \\ Email: rih.nada@ciems.ma \\ Professor Mohammed Guedira \\ University Professor, Université Mohammed V Souissi \\ Email : mohammed.guedira@laposte.net
}

Doi:10.5901/ajis.2014.v3n1p253

\section{Abstract}

Innovation is recognized in the field of entrepreneurship research as an essential component of entrepreneurship. Indeed, the paradigm of innovation is considered one of the oldest in the field of entrepreneurship research and returns to the Austrian school through the work of the economist Joseph Schumpeter (1934). Moreover, innovation is one of the most important entrepreneurial skills (Bayad, Boughattas and Schmitt, 2006). While education programs in entrepreneurship (PEE) main objective is inculcating key entrepreneurial skills to participants, today's debate concerns both the learning content and the methods used. The purpose of this article is to provide an analysis of the transmission of knowledge (mainly tacit knowledge) through PEE's through the integration of its components to Nonaka's model. The role of tacit knowledge in the development of an innovative entrepreneur will be highlighted. The conceptual part of this paper will be focused on the study of the relationship between the concepts of entrepreneurship, innovation and the role of tacit knowledge; the second part will present the PEE components and analyze the transmission of tacit knowledge through the proposition of future research with Nonaka's model.

Keywords: Entrepreneurship, Innovation, Tacit knowledge, PEE, Nonaka model.

\section{Introduction}

Nowadays, entrepreneurship is becoming increasingly important. It is taking a central position in the debate of a large scientific community. The field of entrepreneurship has established solid foundations that have allowed it to consider a more sought theoretical construction.

Research in entrepreneurship has become increasingly guided by the theory built around a central core of topics, issues, methods and debates. The synthetic work of Veciana (1999) shows that most cited theoretical approaches of entrepreneurship are those related to opportunity and personality traits.

Yet, the knowledge economy today recognizes the creativity, innovation and entrepreneurship as key determinants of the modern value system.

Business success, in a modern and dynamic environment, depends mainly on the intensity of creating, sharing and knowledge management. It can range from employee's creativity to leading to organizational innovation.

The main objective of the Knowledge management should be to achieve specific outcomes, such as intelligence sharing, a developed performance and competitive advantage. It can also generate a high level of innovation and entrepreneurial activities (Crnkic et al. 2012).

The concept of knowledge management involves the ability to capture the information relatively quickly in order to allow decision taking.

Once the idea is developed successfully and it becomes able to enter the market, the idea is consequently transformed into innovation. The innovation process can be internal through the development of new products, quality, efficiency ... or external such as entering new markets, sales ....

New ideas are usually acquired through knowledge creation or by the combination of existing knowledge. However, knowledge concerns different parameters such as organizational knowledge, personal knowledge, experience ... yet; individuals are considered as the key to the process of creating new concepts and innovations (Crnkic et al., 2012). 
Creativity is the ability of a reasonable and logical deduction, which should be intrinsic to entrepreneurs as creators of new tests or new activities in existing businesses (intrapreneurship concept). However, creativity doesn't result only from individual's intrinsic qualities but can also result from people's interaction, social relationships and other sources beyond the individual (Crnkic et al., 2012).

Moreover, while learning is the process of resources absorption, innovation is first directed by learning and knowledge. Knowledge management activities can allow understanding relevant questions that may encourage thinking "outside the box" and lead to innovative creativity issues.

To this end, the concept of entrepreneurship has been early linked to innovation by the Austrian school through the work of the economist Joseph Schumpeter (1934) on economic theory. Entrepreneurship and innovation are thus often seen as key drivers of economic development.

The interaction between innovation and entrepreneurship is often seen as clearly linked to Schumpeter's theory. It considers that the entrepreneur can not be understood unless he is placed in the context of innovation's theory.

However, even if innovation is often considered a complex and difficult process to implement, its complexity is considered by some authors as a time related process (Jörg and Hughes, 2013).

Today, business success is often linked to knowledge development, innovation and creativity. These elements allow individuals and organizations to discover and capitalize on opportunities to create new values.

Thus, given that value creation is a central concern of every entrepreneur; innovation, creativity and knowledge have become then the main ingredients of its development.

There are several variables that affect the development of innovation; this work focuses on those related to knowledge management and more precisely to tacit knowledge transmission.

This article proposes to study the acquisition of entrepreneurial skills; especially those related to innovation through entrepreneurship education. The main objective is to analyze the transmission of tacit knowledge in the context of entrepreneurship education programs (EEP) through the integration of its components in the model of Nonaka.

It is assumed that the tacit knowledge is more likely to help develop new ideas that can lead to creativity and innovation.

The definition of tacit knowledge versus explicit knowledge used within this work is based on the model developed by Nonaka and Takeuchi (Nonaka \& Takeuchi 1995).

\section{The Paradigm of Innovation in Entrepreneurship}

Raouf JAZIRI $(2009$, p.3) defines paradigms in the context of entrepreneurship as: "all accepted rules as " standards " by the entrepreneurship's research community, at a given time in order to define and problematize 'facts' considered worth the study. "

To this end, and given the complexity and heterogeneity of the disciplinary field of entrepreneurship, the researchers propose to classify the different author definitions in four schools of paradigms to build a theoretical foundation of the discipline. These paradigms are illustrated in the following graph:

Figure 1: Messeghem's model (2006)

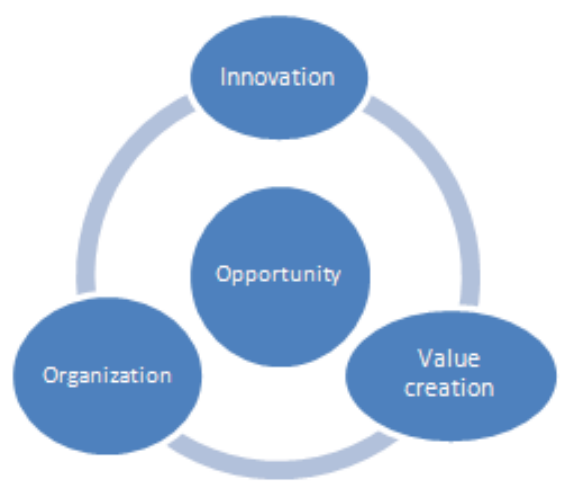

Source: K. Messeghem 2006 page 9.

Before developing the innovation paradigm, which is the main interest of this study, a brief overview of other commonly 
accepted paradigms will be presented to give a comprehensive overview of the field of entrepreneurship.

\subsection{The Paradigm of opportunity}

This paradigm refers in particular to the work of Kirzner offering an entrepreneurial model based on two major Austrian contributions: Mises and Hayek (Messeghem, 2006). Entrepreneurship is defined as the ability to create or identify opportunities and exploit them. This is to assess the ability to gather resources to track evaluate and exploit opportunities. The difference is highlighted between the existence of an opportunity and the identification and exploitation process.

\subsection{The paradigm of organization's creation}

Gartner $(1985,1990$, and 1995) who initiated this paradigm combines the concept of entrepreneurship to the creation of a new organization by one person or a group of people. Within this definition, the concept of organization covers a wider scope than the company's field.

\subsection{The paradigm of value creation or capture of existing value}

Through this paradigm, entrepreneurship is defined as: the phenomenon or process of creating a value which can be individual, economic or social (Ronstadt, 1984; Bruyat and Julien, 2001). This paradigm is also related to the research about the link between entrepreneurship and economic growth.

Bruyat (1993) introduced the concept of entrepreneurial profit through the analyses of the relationship between individuals and value creation. This value creation is defined by the exchange at a market's predetermined price. However, this vision of entrepreneurship would be reduced to the commercial sector while today the value can have a social connotation particularly through the social economy sector for example (Verstraete and Fayolle, 2004).

\subsection{The paradigm of innovation}

This paradigm is considered one of the oldest in the field of entrepreneurship research. It is mainly associated to the Austrian school through the work of the economist Joseph Schumpeter (Jaziri, 2009).

Innovation is defined in the Webster's online dictionary as: "An entire process taking place since the birth of an idea to its realization (product launch), through market research, prototype development and the early stages of production. It is synonymous with "the action of creating out of nothing."

For Jörg and Hughes (2013, p. 222), innovation is simply "doing something new that did not exist before or doing something in a new way".

According to Julien Marchesnay (1996), innovation forms the basis of entrepreneurship where having innovative ideas, to produce new goods and services, is necessary.

This paradigm allocates an important place to innovation in the definition of entrepreneurship. Innovation is the foundation of the company. It can take different forms : new products or services, new sources of raw materials, new methods of production, distribution or sale - new markets - new organization ... It would differentiate leader entrepreneurs from small business owners .

However, in Schumpeter's vision the entrepreneur is often linked to the discovery of radical innovations through which it would be capable of generating a " creative destruction" which allows the introduction of new products and ' business models ' on markets.

In addition, several authors consider that innovation is one of the characteristic functions of entrepreneurship and a condition for value creation.

Other authors have focused on aspects of innovation related to the creation of high-tech enterprises, incubation and economic development research.

All these paradigms, although the relevance or dominance of each paradigm is discussed by the authors, are considered the basis of the theoretical development of the field of entrepreneurship as they can give a global vision of the field.

The diversity of paradigms also allows a wide understanding of the different aspects of a diversified research field like entrepreneurship. She would even take into account the uniqueness and complementarity of each of them.

Moreover, innovation is considered as an entrepreneur's specific tool, the means by which they can use change as 
an opportunity for a different service or business.

Entrepreneurs are seen as major contributors to the economic development, mainly through innovation. This includes the development of new products, new processes, new sources of supply but also the development of new markets and the introduction of new inventions (Mascarell, Garzon, 2013).

Moreover, it is commonly accepted that innovation is a series of learning cycles and it is conducted first by knowledge.

In the context of entrepreneurship, innovation may be the result of the development of an idea and its implementation on the market. This process is conducted by individuals who develop ideas that lead to innovation and bring them back into a new market. It was even suggested that entrepreneur's individual competencies are the same as those found in innovative companies (Marscarell, Garzon, 2013).

\section{Entrepreneurship Education}

In the literature, most researchers link entrepreneurship education to a kind of learning process that aims to influence attitudes, behavior and values or intentions towards entrepreneurship either as a career option or as a way to participate in the development of their role in the community (Mwasalwiba, 2010).

It is also defined as seeking to encourage self-esteem and confidence based on individual talents and creativity while developing the skills and values that will assist students to develop their prospects and opportunities (Radipere, 2012).

The entrepreneurship education should thus provide students with relevant experience and help them gain selfconfidence. It was widely accepted that entrepreneurship education is relevant and contributes to economic development.

Regarding the objectives of entrepreneurship education, development of entrepreneurship spirit, culture and attitudes are the main objectives mentioned by researchers, followed by the creation of startups and jobs, contributing to the company and the acquisition of entrepreneurial skills (Mwasalwiba, 2010).

Moreover, in the literature, there are generally three major educational fields, Jarniou (2008):

1. The know or Knowledge: referring primarily to intellectual knowledge;

2. The know-how: concerning the practical skills obtained through experience in a particular activity;

3. The Know how to act (savoir être): referring to the ability to produce and master actions and reactions adapted to the environment through attitudes and behaviors.

Regarding the types of entrepreneurship education, some authors distinguish four types of entrepreneurship education: entrepreneurship awareness; education for startups, education for entrepreneurial dynamics and continuous training for entrepreneurs.

According to the vision of Gibb (1992), recommended teaching methods can be summarized through the entrepreneurial learning model, namely (cited by Jarniou, 2008):

- Mutual learning (and not just from the teacher);

- Learning by doing;

- Learning by interpersonal exchanges and debates/discussions,

- Learning through guided discovery;

- Learning from different people's reactions;

- Learning in a flexible and informal environment;

- Learning under the pressure of goals achievement;

- Learning by borrowing from others;

- Learning by trial / error;

- Learning by solving problems.

Other authors argue that action pedagogies are the most appropriate for entrepreneurship education.

Biggs $(1996,1999)$ sees the complex education system as a combination of different components: teachers, students, the teaching environment and student learning activities. The challenge for educators is to find consistency between the course objectives, learning activities and assessment activities.

The teaching methods used are often discussed and it appears that the lectures, case studies and discussions are those most commonly used ways. Although the debate on the methods with the most important impact on behavioral change is still valid, it is generally accepted that traditional methods are less effective in changing the behavior of trainees. These methods tend to make of learners "sleeping" participants (Mwasalwiba, 2010).

Moreover, it is very important to adapt the objectives, methods and topics to the enrolled students. It is often said 
that students bring to the classroom an accumulation of motivations, intentions and prior knowledge that affect the learning process and its quality.

Johannisson (1991) identifies five learning entrepreneurship education levels:

- Why Entrepreneurs act? ( their values, motivations ... ) ;

- What must be done? (knowledge);

- How to do it? (abilities and skills);

- Who should we know? (social skills, networks ... ) ;

- When should we act? (Experience, intuition).

The knowledge derived from education leads to a higher capacity to identify most important opportunities and thus increases entrepreneurial attitudes and intentions.

Concerning the content of a typical entrepreneurship courses, it is obvious that each institution has its own approach to develop a curriculum for entrepreneurship education. There are a multitude of modules taught as part of entrepreneurship programs even if the course content must be adapted to the specific needs of students.

According to Souitaris et al. (2007), an entrepreneurship program is broader than just a simple course and it should include a strong portfolio of complementary activities.

In the literature, programs that meet the standards of "best practices" typically include four basic components:

- An educational component ;

- A "Business Plan " component;

- An "interaction with practice" component;

- A support of the university component.

Other popular activities in entrepreneurship courses include interviews with entrepreneurs, analysis of the environment, real case studies, the use of videos and movies or the establishment of students entrepreneurship club.

McMullan et al. (1985) also propose to structure entrepreneurship courses around a series of strategic challenges such as identifying the opportunity, feasibility analysis, new business planning, financing, the development of a new market, expansion strategies and innovation.

\subsection{Teaching methods}

Even if researchers have already answered the question: can entrepreneurship be taught? Today, they have to answer the following question: How should we teach entrepreneurship?

In addition, several authors have focused on the study of teaching methods in entrepreneurship (Izquierdo et al, 2007. Lourenço and Jones, 2006; Poikkijoki and Heinonen, 2006; Robertson and Collins, 2003; McMullan and Boberg 1991), while others were interested in determining the methods that works the most (Verduyn et al, 2009; Hannon, 2006. Van Auken et al, 2006). Fact remains that it is still a matter of discussion among researchers and there is still no consensus on the subject. However, the challenge for entrepreneurship educators remains oriented towards providing learners with resources and experiences that will allow them to face the market's multiple expectations once their project is launched.

The methods used are often classified into two categories: traditional or passive methods and innovative or active methods. Mwasalwiba (2010) identified 36 methods through his work on 21 articles, the results of the study show that the three most common methods are:

- Lectures ;

- Case studies;

- Group discussions.

These methods are however still considered as passive and have less effective impact on entrepreneurial attributes. They are followed by other methods such as:

- Computer simulations;

- Videos and films;

- Guests or models testimonials ;

- Business Plan creation;

- Projects work.

Games and competitions of creating real small businesses, workshops, presentations, etc. are also used. These methods are considered active and are recognized as being more suitable to achieve the objectives of entrepreneurship training. 
Moreover, it is often more appropriate to teach entrepreneurship through experiential learning or "learning by doing" Radipere (2012).

Other authors suggest that the most appropriate style of entrepreneurship education methods are application and active experimentation, which include concrete experience, reflective observation and abstract conceptualization.

Currently, there is a general consensus that students destined for a self-employment career should develop certain abilities. Therefore their training would be more appropriate with activity-based approaches rather than traditional methods. However, it is also recommended not to leave completely aside the theoretical part of the training.

In addition, outside the traditional course, educators will be challenged to find effective learning opportunities for their students in entrepreneurship programs. They must be prepared to face the reality of the market that may be uncertain and unstructured.

To this end, Izquierdo and Buelens (2008) suggest that the most we offer students hands-on learning opportunities with varied experiences to expose them to real situations, the more they can gain confidence to use the skills acquired in various situations through the development of complex skills.

Solomon (2007) states that the challenge of entrepreneurship educators is to combine rigorous academic education while maintaining a basic reality of the environmental climate for business creation. This can allow entrepreneurship education to form business leaders capable of generating a real business development. The pedagogy of entrepreneurship education must take into account the random nature of the entrepreneurial experience.

Entrepreneurship is an ongoing process that requires several talents, skills and knowledge that must be conducted through a stimulating pedagogy likely to transmit valuable knowledge. (Solomon, 2007).

In conclusion, these programs should be directed towards creativity, multidisciplinary approaches, processoriented and practical applications based on theory (Solomon, 2007).

\section{Knowledge Transfer through a PEE : An Analysis through Nonaka's Model}

What kind of skills for an entrepreneur?

The entrepreneur has occupied an important place in entrepreneurship research during the 1960s and 1970s. Following the economists, researchers in sociology and psychology become interested in the entrepreneurship's research domain. They focused in particular on the entrepreneur as an individual and on its personality traits.

Studies on the entrepreneur definition have constituted the first steps of research in entrepreneurship as a scientific domain.

Hébert \& Link (2009) synthesized in 12 points, ideas mentioned by the most famous economists in the definition and function of the entrepreneur:

1. The entrepreneur is the person who can assume the risk associated with uncertainty.

2. The entrepreneur is the provider of financial capital.

3. The entrepreneur is an innovator.

4. The entrepreneur is a decision maker.

5. The entrepreneur is an industrial leader.

6. The entrepreneur is a manager.

7. The entrepreneur is an organizer and coordinator of economic resources.

8. The entrepreneur is a business owner.

9. The entrepreneur is an employer of production factors.

10. The entrepreneur is a contractor or supplier.

11. The entrepreneur is a stock broker.

12. The entrepreneur is the person who allocates resources to alternative uses.

The fact that each author considers the characteristics or traits of the entrepreneur differently leads to a lack of consensus on the definition and function of the entrepreneur.

It was thus natural for entrepreneurship researchers to study entrepreneurs in terms of their personality traits and also to try to isolate what makes entrepreneurs different from non-entrepreneurs. However, recent studies go beyond the distinction between entrepreneurs and non-entrepreneurs trying to identify certain traits as success predictors (Sarasvathy, Venkataram, 2011).

Radipere (2012) noted that speaking of entrepreneurs; we are primarily concerned with their particular behaviors, attributes and skills. And talking about entrepreneurship, we tend to have a process in mind that implies results of a new economic activity introduction. 
The psychological component of entrepreneurs also holds great attention among researchers. They would agree on the fact that entrepreneurs show a high level of motivation and perseverance in their projects (Jaziri, 2009).

The entrepreneur also tends to have a great capacity for creation. He adds value through imitation, reproduction, development, creation or change actions.

For Schumpeter (1934): entrepreneurs constantly modify and develop new markets through an innovative combination of resources.

These entrepreneurial skills can only be acquired through a combination of existing or acquired knowledge. This knowledge can be organizational, personal or from experience.

Indeed, those who attributed entrepreneurial success to the entrepreneur's personality traits have been heavily criticized by the community of researchers who supports that skills are the best determinants of the performance of entrepreneurs (Boughattas, Bayad, 2009).

These skills usually depend on the contextual and personal characteristics of the entrepreneur and are structured around the following components: knowledge, know how skills (professional practice, experience) and life skills (behaviors, attitudes, adaptability).

Boughattas, Bayad $(2009$, p.6) define entrepreneurial skills as: "A set of intentional and motivated skills of an entrepreneur (or an entrepreneurial team) to succeed in a project by coordinating and combining a variety of individual and combined resources".

The entrepreneur's key success factors are identified by other researchers as: personality, motivation and skills.

By analyzing the process of knowledge creation, Naffakhi (2008) distinguishes different learning process and assumes that experience sharing of and exchanges among individuals allow them to have access to new information and lead to the development of tacit knowledge bases.

Interaction is another process that will allow group members to build up a shared understanding. Finally, it is important to mention that negotiation and analysis allow individuals to broaden their horizons of thought and develop new ideas.

The interpretation of the transmitted message can generate new ideas and lead to creativity and innovation. It is then assumed that entrepreneurial skills are the same as those found in innovative companies (Mascarell and Garzon, 2013).

\section{Knowledge Transmission}

Several models, such as the N structure model of Hedlund (1994), the "Organizational Knowledge Network model" of Carayannis (1999), the three-pillar model of knowledge management Wiig (1997), Szulanski's model (2000) tried to explain the creation and the transmission of knowledge. Among these models, Nonaka and Takeuchi's (1995) is the basis for understanding the process of knowledge creation (Naffakhi et al., 2008).

Knowledge is often seen as the appropriation and interpretation of facts, know-how and know how to act (savoir être) of the individual (Naffakhi et al., 2008).

In the model of Nonaka and Takeuchi (1995), knowledge is divided into two types: the tacit and the explicit.

\section{Explicit Knowledge}

The explicit knowledge is defined as the rational knowledge that can be expressed in a clear and transferable form. This knowledge includes theoretical approaches, problem solving, manuals, databases....

Other researchers define explicit knowledge as the articulated and the visible knowledge that can be easily transferred and codified. For example: Documents, drawings, plans, or through information systems.

\section{Tacit Knowledge}

The tacit knowledge is considered as subjective and based on experience knowledge. It cannot be expressed in words, phrases, numbers, formulas.... It is often specific to a given context.

The tacit knowledge includes emotions, feelings and individual intuition as well as personal relationships that can't be easily transmitted. They come from individuals and are hardly transmitted because they include insights and individual impressions. The tacit knowledge is also known as related to beliefs and behaviors that can be transmitted by learning through observation, imitation and experience (Nonaka et al. 1997). 
The articulation of collective tacit knowledge can also lead to the creation of explicit knowledge. They express the individual «know-how" within a group (Naffakhi et al. 2008).

The nature of tacit knowledge is mainly related to the individual information that we do not usually find in books or newspapers. The acquisition can then be facilitated by the use of didactic teaching methods like cases studies, simulations and experience.

Before tacit knowledge can become explicit, it should be codified or articulated. The process can be very difficult. Tacit knowledge has no limits in our brain, even if people want to communicate, they may be unable to do so. In order that transmission becomes possible in an active audience, it is necessary to have enough time and a "face to face" meeting with reliable trustworthy participants (Wright, 2008).

As part of the campus life, extracurricular activities can be considered as a good learning process of tacit knowledge. Indeed, these activities often allow students to be in contact with the social and professional world and develop important personal and professional skills.

Figure 2: Nonaka's model
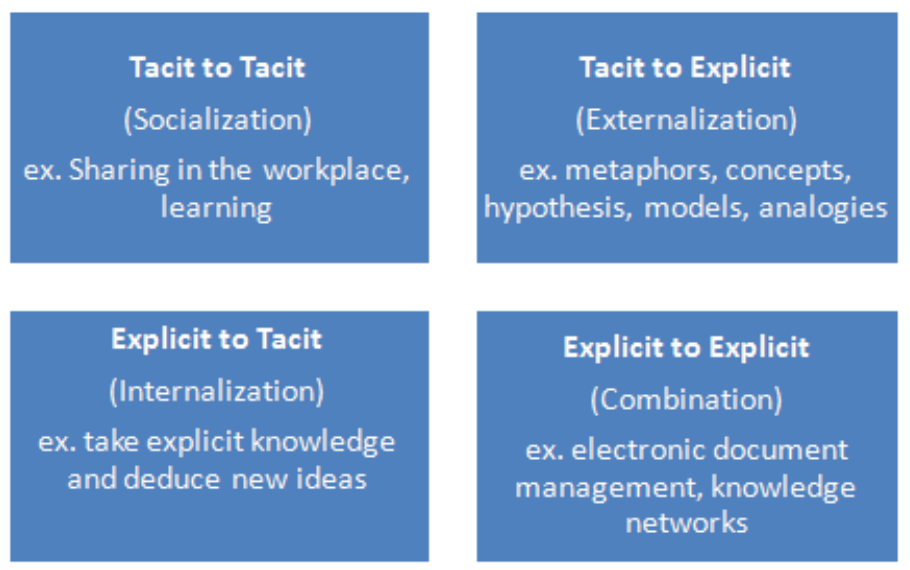

Source : Naffakhi et al. 2008, p.7

Nonaka proposes a model of knowledge transfer in the form of a matrix that considers existing knowledge as tacit or explicit. Knowledge transfer can thus transform them either into tacit or explicit.

These changes are considered as follows:

1. Socialization: refers to the transfer of tacit knowledge from a person to another. This represents the transfer of knowledge such as an experience or knowledge gathered through direct interaction with both internal and external people to businesses;

2. Outsourcing: is the process of transforming tacit knowledge into explicit knowledge. This process can be achieved through the transfer of knowledge, ideas, or images of a person through for example: words, metaphors, or through the transformation of other person tacit knowledge, like experts, to an understandable form which makes it explicit. Outsourcing is a process that takes place among individuals or groups. This helps, in face-to-face situations, to share ideas and beliefs and learn to articulate thoughts through ideas exchange and instantaneous feedback.

3. Combination: Explicit knowledge can be transferred as explicit through the process of combining knowledge. Explicit knowledge can be transferred through documents, emails, databases ... making the role of information technology important at this stage.

4. Internalization: Indicates the process of understanding and absorbing explicit knowledge and transforming it to tacit knowledge. The internalization process allows the transfer of explicit knowledge of a group or an organization to individuals. This knowledge becomes tacit and actionable by the individual.

In the entrepreneurial literature, the concept of knowledge acquisition is often related to action learning (learning by doing) rather than the classic learning through lectures, but also through experimentation that is considered as a set of 
sequences of "trial / error".

Personal knowledge is acquired through the entrepreneur's interaction with the immediate environment. The entrepreneur is in relation with both formal and informal networks that can guide him/her and support him/her in the management of his business and keep him/her informed on market's trends and developments.

Training future entrepreneurs must take into account the intuitive and the informal part of the process illustrated through practice, experience and experimentation.

The entrepreneur must find a balance between the development of the human capital (knowledge, skills and abilities) and the social capital (network and relationships) in an individual and organizational level (Mascarell, Garzon, 2013).

Given these assumptions, the following research question is raised:

Through which PEE's components can tacit and explicit knowledge be transmitted to future entrepreneurs? Can tacit knowledge generate innovation?

The proposed reflection attempts to understand the transmission mode of entrepreneurial knowledge (in the context of a PEE) through the Nonaka's model. The leading role of the acquisition of tacit knowledge by an entrepreneur in the development of innovation is emphasized.

It should be noted that the PEE is not the only variable that is taken into account in the process of acquiring entrepreneurial skills. Yet, it will remain the only analyzed element in this study.

In this model, the considered components of PEE are those proposed by the "Innova Project" a national program launched in 2011 by the Moroccan Ministry of Industry, Trade and New Technologies, whose main objective is introducing entrepreneurship education in higher education system to encourage innovative company creation.

Figure 3: Analysis of components of a PEE through the model of Nonaka and Takeuchi (1995)

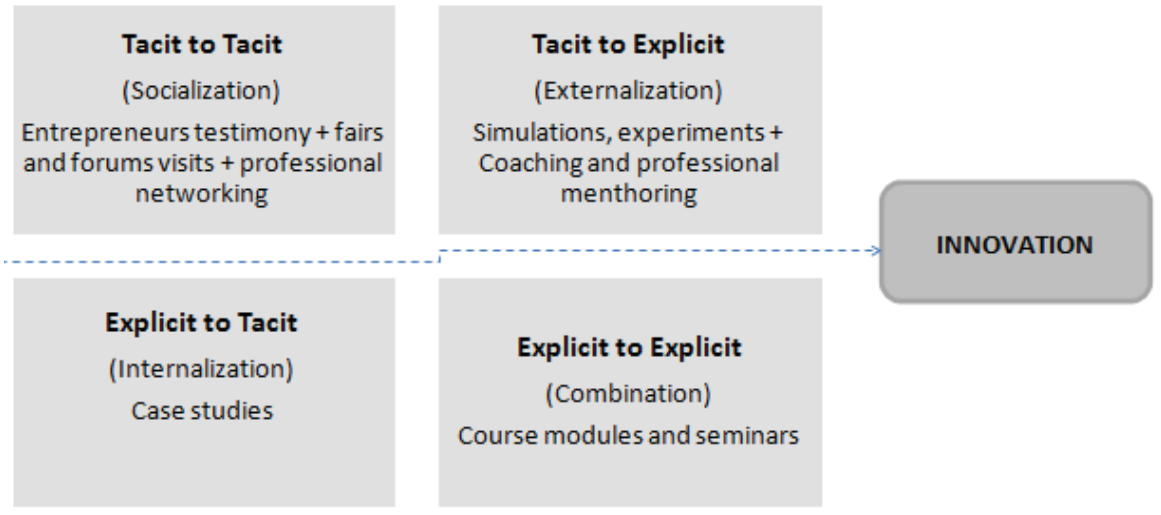

\section{Research proposals}

Proposition 1: Socialization. PEE's modules incorporating situations such as meetings and discussions with professionals or entrepreneurs, visiting trade fairs and forums are assumed to be the most likely to transmit tacit knowledge that will become the receiver's tacit knowledge.

Proposal 2: Simulations, experiments and professional coaching and mentoring will allow the transfer of tacit knowledge that can be formalized and become explicit. The implementation of the knowledge acquired can be applied through the development of a business plan and a business model.

Proposition 3: The case studies present a real case; the resolution of this case will be analyzed by the learner and absorbed according to its own way of understanding. This process will internalize the explicit knowledge which will be transformed into tacit knowledge, which can in turn be adapted and reused by the learner in similar situations.

Proposition 4: The module courses and seminars usually transmit formalized and explicit knowledge that will be integrated by learners in the same form.

It is assumed, in this respect, that some components such as entrepreneur testimonials, coaching and mentoring, visits to trade fairs and forums can transmit tacit knowledge that can lead to creativity and innovation. 


\section{Conclusion}

Different models have focused on the transfer of knowledge between individuals and within a group. This transmission is done through mechanisms that allow the accumulation of knowledge by an individual or through interaction between individuals or group members which can allow access to new information and tacit knowledge. However the transmission process, which is the transfer of information from a sender to a receiver, is dependent on the individual abilities to understand the message. It is the individual interpretation that differs from an individual to another, especially when it comes to generating new ideas, creativity and innovation.

The interaction between individuals and the transmission of real-life experience would lead to better innovation performance. Madhoushi et al. (2011) argues that entrepreneurial orientation influences the innovation performance through Knowledge management both directly and indirectly. Knowledge management would be considered as a mediator between entrepreneurial orientation and innovation.

In an increasingly saturated market, both at the national and international level, entrepreneurship is inextricably linked to innovation. Whether in terms of products, services, processes, distribution or at the level of the business model, innovation becomes an important business success factor for the firm. It allows individuals and organizations to identify and exploit opportunities through a new way of creating value.

Several authors have studied the impact of entrepreneurship education programs in general; a few, however, have been interested in investigating the impact of each component of the program on the studied variables. It is interesting to study the impact of each of these components in order to assess their relevance and to continuously improve the content.

Nonaka's model allows us to understand the transmission of knowledge in the context of a company in a very practical way. This can lead to an in-depth reflection on the contribution of each component of a training program in entrepreneurship. Moreover, it is clear, as often cited in the literature of entrepreneurship education, that some methods should be preferred in these programs. These would be capable of transmitting tacit knowledge (in the form of experiences, personal capabilities ...) instead of explicit knowledge that aspiring entrepreneurs can find in books and manuals. Participation in conferences, fairs, forums, etc. can allow future entrepreneurs to explore the business environment, discover opportunities and have new ideas that can lead to creativity and innovation. This knowledge is crucial in entrepreneurship, given the importance of real experiences.

This problem can be further explored through the study of the appropriate means of transmitting tacit knowledge through a PEE and the role of knowledge in stimulating innovation and creativity.

\section{Acknowledgement}

A short version of this paper is published in french language in " la Revue Marocaine de Recherche en Management et Marketing " in 2004.

\section{References}

Boughattas Y. et Bayad M. (2009), « Le processus d'acquisition des compétences entrepreneuriales », 20e Congrès AGRH, Toulouse. Coster M. (2009), « Entrepreneuriat », Pearson France.

Crnkic K., Cizmic E., Sunje A. (2012), « Knowledge management and innovation as driving forces behind successful entrepreneurship », 6th International Conference of the School of Economics and Business, University of Sarajevo, School of Economics and Business, Bosnia and Herzegovina, October 12-13, 2012.

Hébert R. F., Link A. N. (1988), « The Entrepreneur: mainstream views and radical critics », Praeger Publishers; 2 Sub edition (August 24, 1988).

Izquierdo E., Buelens M. (2008), « Competing Models of entrepreneurial intentions: the influence of entrepreneurial self efficacy and attitudes », Internationalizing Entrepreneurship Education and Training, IntEnt2008 Conference, 17-20 June 2008, Oxford, Ohio, USA.

Jarninou C. L. (2008), « Développer la culture la culture entrepreneuriale chez les jeunes », Revue française de gestion - № 185/2008.

Jaziri R. (2009), «Une vision renouvelée des paradigmes de l'entrepreneuriat : Vers une reconfiguration de la recherche en entrepreneuriat », Actes du Colloque International sur : «Entrepreneuriat et Entreprise: nouveaux enjeux et nouveaux défis». 3-45 April 2009, Gafsa.

Jörg T. and Akkaoui Hughes S. (2013), « Architecting the dynamics of Innovation », Proceedings of the international Conference on Intellectual Capital, Knowledge Management and organizational learning. P.222-230.

Johannison, B., (1991), "University Training for entrepreneurship: Swedish Approaches ». Entrepreneurship and Regional Development, 3:1, pp67-82. 
Madhoushi M., Sadati A., Delavari H., Mehdivand M., Mihandost R. (2011), «Entrepreneurial Orientation and innovation performance: the mediating role of Knowledge management », Asian Journal of Business Management, 3 (4): 310-316.

Mascarell C.S. and Garzon D., Knorr H. (2013), « Entrepreneurial and innovative competences, are they the same? », Management Decision, vol.51 N 5, pp. 1084-1095.

Mwasalwiba E.S. (2010). « Entrepreneurship education: a review of its objectives, teaching methods, and impact indicators », Education + Training, Emerald Group Publishing Limited.

Messeghem K. (2006), «L'entrepreneuriat en quête de paradigme : apport de l'école autrichienne », 8ème congrès international Francophone en entrepreneuriat et PME.

Naffakhi H., Bayad M. et Boughattas Y. (2008), « Processus de création de connaissances au niveau des équipes entrepreneuriales : illustration par le modèle de Nonaka et Takeuchi », 9e CIFEPME, Congrès International Francophone en Entrepreneuriat et PME.

Radipere S. (2012), « South African university entrepreneurship education », African Journal of Business Management, Vol. 6(44), pp. 11015-11022, 7 November, 2012.

Sarasvathy S. D. and Venkataraman S.(2011), «Entrepreneurship as Method: Open Questions for an Entrepreneurial Future », Entrepreneurship Theory and Practice, January 2011.

Solomon G. (2007), "An examination of entrepreneurship education in the United States", Journal of Small Business and Enterprise Development, 14(2), p 168-182.

Vangelis Souitaris a. *, Stefania Zerbinati b,1, Andreas Al-Laham c,2, "Do entrepreneurship programs raise entrepreneurial intention of science and engineering students? The effect of learning, inspiration and resources", Journal of Business Venturing 22 (2007) $566-591$.

Veciana J.M. (1999), "Entrepreneurship as a scientific research program", Entrepreneurship: concepts, theory and perspective.

Verstraete T. et Fayolle A. (2004), «Quatre paradigmes pour cerner le domaine de recherche en entrepreneuriat », 7ème Congrès International Francophone en Entrepreneuriat et PME, Montpellier.

Wright H. (2008), "Tacit Knowledge and Pedagogy at UK Universities Challenges for Effective Management", The Electronic Journal of Knowledge Management, Vol.6, Issue 1, pp.49-62. 
